\title{
What pharma wants
}

\author{
Klaus Wilgenbus, Ray Hill, Alan Warrander, Sanjay Kakkar, Eva Steiness \& Rainer Wessel \\ Pharma has pipelines to fill and cash to spend. But just what types of partners and products is it looking for?
}

\begin{abstract}
W ith pharmaceutical companies partnering with biotechs at a heated pace, biotechs are considering the factors used in benchmarking drugs and wondering what are the best ways to present programs under development. In this article, two pharmaceutical executives, three biotech CEOs and a healthcare veteran provide insights into today's partnering environment. What follows is an abridged transcript of a Bioentrepreneur roundtable discussion convened at BIOEurope 2006 at the Hilton Hotel, Dusseldorf, Germany on November 5, 2006, which was sponsored by Merck, based in Whitehouse Station, New Jersey. The following transcript has been edited to address the major themes discussed.
\end{abstract}

\section{What are the key ingredients in licensing deals?}

Ray Hill. Merck has not been involved in a mega-merger and hence these days [it] could be considered a medium-sized, rather than large, pharmaceutical company. Nevertheless, we still have 9,500 staff in R\&D and we spend $\$ 4.8$ billion. Even with this large investment in $\mathrm{R} \& \mathrm{D}$, we estimate that we do internally about $1 \%$ of the biomedical research that we need to know about. So clearly we've got to be outward looking. At the same time, we need to focus and only run one set of R\&D objectives. Essentially, the nine therapeutic areas [Alzheimer's disease, atherosclerosis, cardiovascular disease, diabetes,

Klaus Wilgenbus is at Boehringer Ingelheim, Binger Str. 17355216 Ingelheim, Germany. Ray Hill is at Merck, Sharp and Dohme, Hertford Rd., Hoddesdon, Herts, UK EN11 9BU. Alan Warrander is at Wood Mackenzie, 5th Floor, 1 Finsbury Square, London EC2A 1AE, UK. Sanjay Kakkar is at Trigen, Emmanuel Kaye Building, Manresa Rd., London SW3 6LR, UK. Eva Steiness is at Zealand Pharma, Smedeland 26 B, 2600 Glostrup, Denmark. Rainer Wessel is at Ganymed Pharmaceuticals, Freiligrathstrasse 12, D-55131 Mainz, Germany.

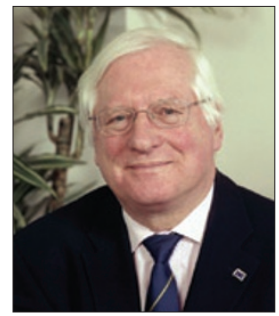

Ray Hill is executive director and head of licensing and external research at Merck

Sharp \& Dohme, the UK subsidiary of Merck $\&$ Co.

ture capitall community. We also have defined 'wants' in the technology arena, because drug discovery is still a competitive high-tech area, and without enabling technology, you can't move it forward.

But when in doubt come and talk to us. When you get a product to phase 2 clinical proof of concept, even if it comes from a strategy that we've decided we don't want to work on internally, we're happy to admit that we're not always right and would be happy to review a data package. And phase 2 clinical efficacy wins every time.

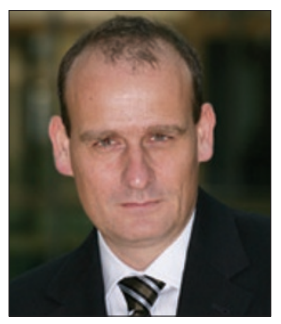

Klaus Wilgenbus is senior vice president, licensing, at Boehringer Ingelheim. and I was hired by big pharma with the expectation that the next wave of new drugs will be built on genomics. And there was this huge hype at the beginning of the late nineties around genomics, and I think it was a very sobering experience for many of us because there were huge expectations built around a certain technology that just could not fulfill the promise. So we don't want companies approaching us, or third parties approaching us, vastly overselling their assets. Be real with what you have and let the data speak for themselves.

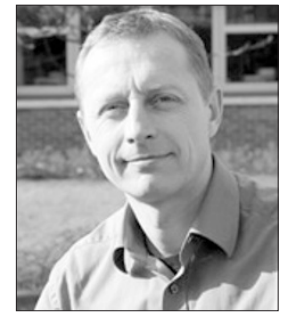

Rainer Wessel is president and CEO of Ganymed Pharmaceuticals.
Rainer Wessel. For us, what we normally do is we outline what we have done, and then we make it transparent what we are going to do, let's say for a horizon of the next 12 to 18 months. Go in there with a presentation describing that, and then pharma will come back later, in a year or a year and a half and see whether you have done what you promised. Most companies are really following what you are doing, and so you have to build up a certain reputation and then really deliver on that expectation.

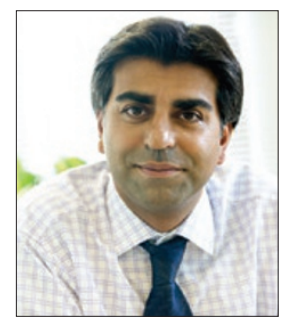

Sanjay Kakkar is CEO of Trigen.
Sanjay Kakkar. I entirely agree with Rainer that it's about building up a relationship. I think we all know that, I think we're all mature enough now in this sector, or I hope we are, to understand that you don't get a deal after the first meeting, and don't expect anything to happen quickly. But you can lay out broadly what the opportunity is for your product, and where it is. 
It really is about being realistic and understanding your objective, understanding what stage your drug actually is, and what the costs and the risks of getting it to market are, and then understanding your buyer. Really understand what they're after and position your drug as such.



Eva Steiness is CEO of Zealand Pharma.
Eva Steiness. When our team at Zealand Pharma [Glostrup, Denmark] went to out-license an interesting compound, we knew where we were, and we knew what we hadn't done. Big pharma showed up and we did a due diligence with five big companies in one and a half months — that was a burden, I can tell you. But they asked questions relating to their internal barriers for moving one compound to the next step. And being a small biotech company, I can say I think big pharma has to learn who they are talking to. Because biotech is built on venture funds and they don't allow us to do a lot of the things that pharma wants.

R.H. When looking at a product opportunity, it really comes back to this issue of how badly do we want it? And each case is different. If the presented opportunity is in an area where we already have a high degree of commitment internally and especially if the biotech is ahead of where we are internally, then we probably would jump in very early with an expression of interest. If we are cynical about the value of the target, then we're going to stand back and say, "We want to see your phase 2 data." But if we're already convinced that it's a great target, then yes, we will enter early-stage collaborations with a suitable partner.

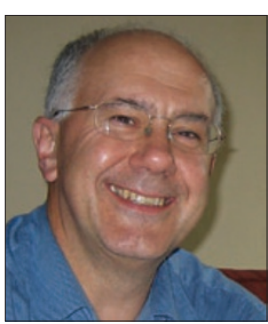

Alan Warrander. I can think of one deal that I was involved in when I was still with AstraZeneca where we felt that the compound was no more than a proof of principle, something to test Alan Warrander is senior vice president, life sciences, Wood Mackenzie. a concept with, and it had CMC [chemistry, manufacturing and controls] problems like nobody's business. But nevertheless, we did a collaborative agreement. The company that we dealt with continued, with AstraZeneca's [London] help, to do basic research and look for backup molecules. We moved the lead molecule forward quickly with what I thought at the time was an amazing formulation, we took it into the clinic, it actually was quite successful in the clinic and the compound is continuing to run. So, yes, every case is different.

\section{What is the deciding factor in striking partnerships?}

K.W. It's all driven by data. However, I-and not just Boehringer Ingelheim but also our peers-also believe that when we talk to smaller companies, which have completely different needs in terms of pushing things forward, they sometimes have certain gaps in the data. That's not to say there are flaws, but there are gaps. To accept this and go forward into clinical development, we need to understand that we can't expect the same breadth and depth of data from a small biotech company. They, of course, did not do 20 pharmacology studies, which is what we'd do for an internal program.

A.W. I think on the big pharma side, they've got to be open and honest with people in the initial discussions and tell them what their processes are. And if it happens that the process and pharma's requirements are not going to fit with what you as a biotech are looking for, and the timeline isn't going to work for you, then you don't need to keep talking to that company. There are lots of other potential partners out there. But I think one thing that's true is that very often in big pharma, the most difficult negotiation is the internal one.

Because the people representing the biotech opportunity are presenting programs that may have fewer data than internally their pharma colleagues are used to seeing. And so what that does is increase the risk; it doesn't necessarily make it less attractive, but it will affect the valuation. Either pharma will come back and say, "Look, we're really interested in this but we want to see you do the following studies." Or, they'll say, "We're really interested in this but we feel we really have to go away and do these studies. Therefore, this is the value that we're putting on your program." So again it comes back down to communication.

\section{What if a biotech's product looks promising but the data are incomplete?}

R.H. Well, at the end of the day it's still all about how much you want something. And if you've come up with an attractive hypothesis internally, and for one reason or another you just haven't been able to find an active molecule that interacts with that target, and you find that a biotech has managed to succeed, then almost any amount of data would be sufficient, so long as they've achieved that initial chemical feasibility or biological feasibility. I think if it's a project where you have an interest in the therapeutic area, but perhaps the mechanistic target is one that you're not terribly keen on, then I think you're going to be a lot more demanding and you'll want to see more data from your potential partner, because you've still got reservations about whether this is a good hypothesis or not.

And I don't see any reason why you can't say, "We had an internal program on this five years ago, and really we were not impressed with the molecules we produced and we dropped it." I think you should share that information with your potential partner, and say, "That's why we're not going to take an interest in a project from outside until you have clinical data, because our own preclinical project wasn't that impressive." And I think you'll find that big companies might be keen on what you're doing, even if you have a very limited toxicology package or even a limited amount of in vivo data. For example, in the obesity area, our gold standard test has been dietary-induced obesity in the rat. That can be a very expensive test that a small company would probably have to pay to have run by an external service provider. But if you come along with an active molecule that you're prepared to supply under MTA [material transfer agreement] and it works at a target we're really interested in, we'll do those studies at our expense. And even if we decide not to go forward, you get those data without paying a CRO [contract research organization] for it. So I think that there are ways forward in most of these issues, if you get the right sort of open and transparent discussion about the needs of both potential partners.

S.K. What you're asking is for that corporate entity to risk $\$ 500$ million to $\$ 1$ billion to move into or extend the therapeutic franchise with a product where the costs and the risks are huge, even at the early stages, even at phase 2 . And I think this is a problem because what we do as biotech companies is say we're expecting you to do all of this, whereas pharma is saying, "Hold on, it's not ready for us to make that commitment, we have to be able to see a little bit more data, we have to spend more, we have to see the CMC, we have to see the formulation." And I think that a fundamental flaw is that you've got biotech companies that have pushed a certain distance, and our finance will go a certain distance and the expectation of what can be delivered at that point when that financing is complete is lacking in terms of what pharma will commit to at that particular point. 
K.W. What you have to sell to your partner is strategic fit. And the good biotechs actually approach us and say, "We know you have this product there that runs out of patent in 2012, we don't see anything in your pipeline, we believe you should be interested in this compound." And then we say, "Yes, you're right," because we have a gap. That's a strategic fit. So that might make us the right partner to do it because we'll be committed. This will help us convince our partner that we will not just shelve it, but that we will develop it because there is a need for both of us to bring this compound to the market as soon as possible.

E.S. The really big problem I see for small biotech is the CMC section, because we need to upscale and that's pretty expensive, and you need to do that in the right timeframe, and that's close to being impossible. We all have to fit with the safety package for clinical development, and I think that biotech companies don't want to minimize that, and that goes for the tox [toxicology] studies, too. But the CMC section I think that is, at least from our experience, one of the major differences between big pharma and smaller firms.

R.H. At Merck, we've gotten to the point where, through an acquisition, we have a compound that is now ready for its first indication. And we have three things in phase 2 and a very strong pipeline. And that's been driven by a very aggressive licensing strategy. But there are things in oncology, like antiangiogenic agents, where we'll just tell you we don't go there; we don't do that. But if you come along with something with phase 2 efficacy without any of the caveats and safety worries that we have about that strategy, then we'll put our hands up and say, "We were wrong and maybe there ought to be a compound with that mechanism in our portfolio." But you can't work on everything and you can't be committed to every hypothesis. And I think we have to share that with our potential partners.
A.W. Certainly, when I was at AstraZenecain the oncology and infection area-what we did was identify mechanisms that we were particularly interested in. And we were proactively going out and seeking people who had those opportunities, to find out exactly where the programs were and what they looked like. As a consequence of identifying things we did want, we also had things we really weren't that interested in. And if somebody came along with one of those then it was a case of telling them, "Thanks very much but for these reasons..." But did we publish a list of mechanisms that we did want? No, we didn't. And the reason for that was a lot of it overlapped with what was happening in our own research. And we weren't going to tell the competitors exactly what areas we felt were particularly important.

\section{Does big pharma's interest in biologics signify a shift for healthcare?}

R.H. At Merck we went from a culture where we were very much a small-molecule company with the mantra of "one milligram, one tablet, once a day.” Now you'll find we're equally receptive to biological approaches using proteins, including antibodies or si[smallinterfering]RNAs. Our senior management in $R \& D$ has changed and we have a whole different team leading our efforts. Overall, that change in thinking has taken several years in our big company. One advantage of collaboration with the biotech sector is that cultural changes are achieved in weeks or months in a small company and the large pharma partner can benefit from that agility.

K.W. It is not just Merck who has made this transition, but the whole pharmaceutical industry. We are currently witnessing a tremendous endorsement by big pharma, including Boehringer Ingelheim, for large molecules and biologicals. With that we are seeing the merging interest in big biotech and big pharma to bring tomorrow's therapies to the market. There is the common challenge for both to bring true innovations to the market, and we are eventually all in the same boat. In the end, therapeutic advances and not metoo's will drive future pharmaceutical markets. Maybe that's good news for patients, that we all have to act in concert.

S.K. I'm not sure I actually agree with that. I think that society has shown quite clearly that it's not prepared to accept the risk associated with innovation. We see regulators and we see the issues with new therapies coming through, and even the smallest incidence of side effects will have a dramatic effect on how that drug is received, viewed, how it's labeled. I think actually you do see companies succeeding with me-too products. Look at the statins market, the way the statins market has grown and grown and grown. And one could actually argue over the incremental benefit at each point. I don't see me-too as being a situation where there's actually no benefit at all. Most blockbusters have been built on the basis that the first product and second product get there, they establish the approach, establish the marketplace, and then the next company comes along with an incremental benefit. It could be a slightly lower side-effect profile, it could be slightly better efficacy, it could be a better dosage form, but it's something that the market recognizes as something they'll pay for. So I'm not so sure that innovation is rewarded. I think we see that the risk associated with innovation, even once products get to market, are being treated very cautiously in our society now.

R.H. I think we've got into a discussion that to some extent is the dilemma of the pharmaceutical industry right now. What should you work on? Should you pick things you know that you're going to get reimbursed for, or should you pick things which are truly scientifically innovative? Obviously, in an ideal world you'd like to do both. 